\title{
Functional foods: concepts and application to inulin and oligofructose
}

\author{
Marcel B. Roberfroid* \\ Université Catholique de Louvain, Brussels, Belgium
}

\begin{abstract}
A food can be regarded as functional if it is satisfactorily demonstrated to affect beneficially one or more target functions in the body, beyond adequate nutritional effects, in a way which is relevant to either the state of well-being and health or the reduction of the risk of a disease. Health claims are expected to be authorized for functional foods based either on enhanced function (type A claim) or disease risk reduction (type B claim). Their development is a unique opportunity to contribute to the improvement of the quality of the food offered to consumer's choice for the benefit of his well-being and health. But only a rigorous scientific approach producing sound data will garantee its success. The functional food components that are discussed in the proceedings of the 3rd ORAFTI Research Conference are the inulin-type fructans, natural food components found in miscellaneous edible plants. They are non-digestible oligosaccharides that are classified as dietary fiber. The targets for their functional effects are the colonic microflora that use them as selective 'fertilizers'; the gastrointestinal physiology; the immune functions; the bioavailability of minerals; and the metabolism of lipids. Potential health benefits may also concern reduction of the risk of some diseases like intestinal infections, constipation, non-insulin dependent diabetes, obesity, osteoporosis or colon cancer. The present proceedings review the scientific data available and, by reference to the concepts in functional food science, they assess the scientific evidence which will be used to substantiate health claims.
\end{abstract}

Functional foods: Health claims: Prebiotics

\section{Introduction: nutrition at the turn of the new century}

Functional food has been introduced as a new concept because the science of nutrition itself has changed. During the twentieth century, nutrition has discovered the essential nutrients and it has established nutrient standards, dietary guidelines and food guides, mainly if not exclusively with the aim of preventing deficiencies and of supporting body growth, maintenance and development (Welsch, 1996). More recently it has also made recommendations to avoid excessive consumption of some of these nutrients after recognizing their potential role in the etiology of miscellaneous (mostly chronic) diseases (James, 1988; Food and Nutriton Board, 1989). Through these developments, one of the major contributions of nutrition in the twentieth century has been the concept of balanced diet: 'an appropriate mixture of food items that provides, at least, the minimum requirements of nutrients and a few other food components needed to support growth and maintain body weight, to prevent the development of deficiency diseases and to reduce the risk of diseases associated with deleterious excesses' (Welsch, 1996).

But at the turn of the twenty-first century, at least in the society of abundance, which characterizes most of the occidental and industrialized countries, and even though a balanced diet remains a major recommendation, new challenges have appeared: from exponentially growing costs of health care, increasing life expectancy, improving scientific knowledge, developing new technologies to major changes in lifestyles. Nutrition must adapt by developing new concepts. Optimized nutrition (Milner, 2000) is one such new concept. It aims at maximizing physiological as well as the psychological functions of each individual through nutrition, in order to ensure both well-being and health but, at the same time, a minimum risk of disease through lifespan. It is in this context, that 'functional food' has been proposed as one practical approach to improve diet.

\section{Functional food: the concepts (Diplock et al. 1999)}

Because a wide variety of food products are or will, in the

Note: This paper introduces proceedings of a research conference on 'Recent Scientific Research on Inulin and Oligofructose' organised by ORAFTI, Belgium, which took place in London in February 2001. This conference reviewed the scientific data available, at the time of the conference, on inulin and oligofructose. These terms, which are defined in this introductory paper are used in all the papers to identify linear $\beta 2-1$ fructans which are presently used as food ingredients.

* Corresponding author: Professor M. Roberfroid, fax +32 104593 01, email roberfroid@pmnt.ucl.ac.be 
future, be characterized as functional food with a variety of components affecting a variety of body functions relevant to either a state of well-being and health and/or to the reduction of the risk of a disease, the term functional food does not correspond to a single well-defined/wellcharacterized entity. Rather, it has to be understood as a concept that appears as quite unique. It belongs to nutrition and not to pharmacology and it deserves a category of its own, a category different from nutraceutical, $\mathrm{f}(\mathrm{ph})$ armafood, medifood, designer food or vitafood. Functional foods are and must be foods not drugs, they have no therapeutic effects. Moreover their role regarding disease will, in most cases, be in reducing the risk rather than preventing it. It means that, by recommending the regular consumption of a functional food as part of the usual recommended diet, it is scientifically plausible that, at the population level, the likelihood of getting a particular disease will be significantly reduced.

It is in that general context that an EU Concerted Action on Functional Food Science in Europe (FUFOSE) coordinated by ILSI Europe developed and reached a Consensus on Scientific Concepts of Functional Foods that was published in 1999 (Diplock et al. 1999). This European consensus document proposes the following working definition: 'A food can be regarded as functional if it is satisfactorily demonstrated to affect beneficially one or more target functions in the body, beyond adequate nutritional effects, in a way that is relevant to either improved stage of health and well-being and/or reduction of risk of disease. A functional food must remain food and it must demonstrate its effects in amounts that can normally be expected to be consumed in the diet: it is not a pill or a capsule, but part of the normal food pattern'. That definition describes all main features of functional foods. It is aimed at stimulating research and development in the field of nutrition so as to contribute adequately to the scientific knowledge that will be required to set the basis for an optimized nutrition.

From a practical point of view, a functional food can be:

- a natural food

- a food to which a component has been added

- a food from which a component has been removed

- a food in which the bioavailability of one or more components has been modified, or

- any combination of these possibilities.

\section{Functional food: the strategy for development (Diplock et al. 1999)}

Being foods, functional foods need to be safe according to all criteria defined in current food regulations. But in many cases, new concepts and new procedures will need to be developed and validated to assess functional food risks. In Europe, some, but certainly not all, functional foods classify as Novel Foods.

As described in the European Consensus Document (Diplock et al. 1999): 'The design and development of functional foods is a key issue, as well as a scientifc challenge, which should rely on basic scientific knowledge relevant to target functions and their possible modulation by food components.' Emphasis is then put on the importance of: 'the effects of food components on well-identified and well-characterized target functions in the body that are relevant to well-being and health issues, rather than, solely, on reduction of disease risk.' By reference to basic knowledge in sciences, such a development requires the identification and, at least partly, the understanding of the mechanism(s) by which a potential functional food or functional food component modulates target function(s) that is/are recognized or proven to be relevant to the state of well-being and health, and/or the reduction of a disease risk. Epidemiological data demonstrating a statistically validated and biologically relevant relationship between the intake of specific food components and a particular health benefit will, if available, be very useful. As a conclusion, a functional effect will be demonstrated, and it will serve to formulate hypotheses to be tested in human nutrition studies aimed to show that adequate (in terms of dose, frequency, duration...) intake of the specified food will improve one or more target functions, that are, either directly or indirectly in terms of a valid marker, relevant to an improved state of well-being and health and/or to a reduced disease risk.

The new-generation human nutrition studies should be hypothesis-driven, they should aim at testing the effect of a food as part of the ordinary diet to be consumed, in most cases, by the general population or, generally large, at risk target groups and they should not use a risk versus benefit approach. Most of these studies will rely on change(s) in validated/relevant markers to demonstrate a positive modulation of target functions after (longterm) consumption of the potential functional foods. A (double) blind type of design based on parallel groups rather than crossing-over will generally be appropriate. Data of these studies should be collected and handled according to standards for data management, and data analysis should prove statistical, but perhaps most importantly, biological significance. The markers to be used for the development of functional foods need to be identified and validated for their predictive value of potential benefits to a target function or the risk of a disease.

\section{Functional foods and claims: communication and scientific challenges}

As stated in the European consensus on scientific concepts of functional foods (Diplock et al. 1999): 'As the relationship between nutrition and health gains public acceptance and as the market for functional foods grows, the question of how to communicate the specific advantages of such foods becomes increasingly important.' Its importance also lies in avoiding problems associated with consumer confusion about health messages. Regarding functional foods, claims associated with specific food products is the preferable mean of communicating to consumers, provided these claims are true and not misleading, as well as scientifically valid, unambiguous and clear. Even though a general definition of claim is widely accepted in the field of nutrition, as: 'any representation, which states, suggests or implies that a food has certain characterisitics relating to its origin, nutritional properties... or any other quality' (Codex Alimentarius, 1991), one of the difficulties in 
communicating the benefits of functional foods is that distinct types of claims exist, and that especially the term 'health claims', that is traditionally used to communicate the benefits of foods, is understood differently in different part of the world. Seeking for clarity, Codex Alimentarius has recently classified and defined four different categories of claims (i.e. claims that relate to dietary guidelines; claims that relate to nutrient content; claims that are comparative; and claims that describe nutrient function; but excluding the term 'health claim'). These claims refer to known nutrients and their role in growth, development and normal functions as well as to the concept of adequate nutrition. They are based on established, widely accepted knowledge but they do not refer to a particular effect over and above that expected from consuming a balanced diet. These claims are thus not really helpful to communicate the specific benefits of functional foods. Indeed the claims for functional foods should be based on the scientific classification of markers (indicators and/or factors) for target functions and on the effects on these markers. If such an effect, that goes beyond what could be expected from the established role of diet, concerns a target function or a biological activity without direct reference to a particular disease or pathological process, claim will be made for an enhanced function. But, if the benefit is clearly a reduction of the risk of a disease or pathological process, claims will be made for a disease risk reduction. These two types of claims, that are specific for functional foods, are the type $A$ and type $B$ claims respectively (Diplock et al. 1999).

One of the major issues, still to be resolved especially with these two types of claims, concerns the biological level at which evidence can be accepted as 'satisfactorily demonstrating' an enhanced function or a reduction of disease risk. This evidence should rely on all data available that can be grouped in three categories:

- biological observations,

- epidemiological data, and

- intervention studies, mostly based on markers.

All supporting evidence should, however, be:

- consistent in itself

- able to meet accepted scientific standards of statistical as well as biological significance, especially doseeffect relationship, if relevant

- plausible in terms of the relationship between intervention and results, especially in terms of mechanism(s) of action

- provided by a number of sources (including obligatory human studies) that give consistent findings able to generate scientific consensus.

\section{Inulin and oligofructose: are they functional foods?}

Inulin is naturally present in a large variety of plants. The plant species currently used by the food industry to produce inulin belongs to the Compositae; it is chicory (Cichorium intybus) (De Bruyn et al. 1992). Chicory inulin is a mixture of oligo- and polymers in which the number of monomers (essentially fructose) referred to as

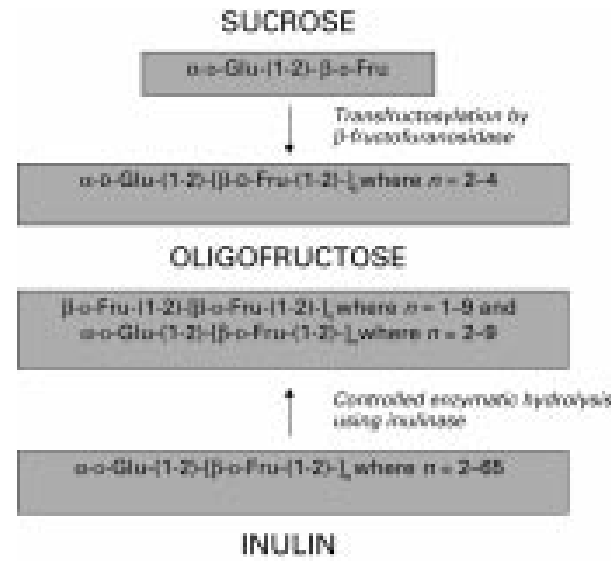

Fig. 1. Schematic representation of the chemical structure and origin of inulin and oligofructose. Glu and Fru represents glucosyl and fructosyl monomers respectively. $n$ is the number of monomers.

the degree of polymerization (DP), varies from two to more or less sixty units. From native chicory inulin the food industry produces a variety of products which are described in the review paper by A. Franck (2002). When enzymatically hydrolyzed inulin produces oligofructose that can otherwise be obtained by enzymatic synthesis (transfructosylation) using sucrose as a substrate (Fig. 1). All these products, which are also named fructooligosaccharides (FOS), differ by the average degree of polymerization (from 3 to 5 for oligofructose up to 25 for some types of inulin). They are classified as dietary fiber and are widely used in a variety of food products both for their technological and nutritional attributes. The terms inulin and oligofructose will be used to identify these compounds in all the papers. For oligofructose however, and when appropriate, it will be indicated if the compound under study is derived from sucrose.

The proceedings of the 3rd ORAFTI Research Conference which are published in this issue of the British Journal of Nutrition review the scientific data concerning inulin and oligofructose which were available at the time of the conference (February, 2001). They report the view of experts in the field of nutrition, especially dietary fiber and functional foods, regarding the technological but mainly the nutritional properties of these food ingredients. They should serve as part of the scientific dossier required to scientifically substantiate the classification of inulin and oligofructose as functional foods and their claims.

Inulin and oligofructose are linear $\beta 2-1$ fructans (Roberfroid \& Delzenne, 1998; Roberfroid \& Slavin, 2000). They are present in significant amounts in several fruits and vegetables (Van Loo et al. 1995) and their average daily consumption has been estimated to be between 1 and $4 \mathrm{~g}$ in the US (MoshFegh et al. 1999) and 3-11 $\mathrm{g}$ in Europe (Van Loo et al. 1995), the most common sources being wheat, onion, banana, garlic and leek.

Because of the beta configuration of the anomeric $\mathrm{C}_{2}$ in their fructose monomers that form $\beta$ 2-1 glycosidic linkages, inulin and oligofructose are resistant to hydrolysis by human small intestinal digestive enzymes, which are specific for alpha glycosidic linkages. These carbohydrates have indeed been classified as 'non-digestible' oligosaccharides (Delzenne 
\& Roberfroid, 1994; Roberfroid \& Slavin, 2000). Both in vitro (Alles et al. 1996; Ziesenitz \& Siebert, 1987) and in vivo (Molis et al. 1996; Ellegärd et al. 1997; Knudsen \& Hessov, 1995) data support this classification. Moreover, there is no evidence that they are absorbed to any significant extent. But inulin and oligofructose are fermented by bacteria colonizing the large bowel as shown by a large number of in vitro and in vivo studies which, in addition, confirm the production of lactate and shortchain carboxylic acids (mainly acetate) as end-products of the fermentation (Alles et al. 1996; McBain \& Macfarlane, 1997). Furthermore, on the basis of the results of well-designed human studies that have shown significant changes in the composition of human faecal flora, it can be concluded that inulin and oligofructose $(5-15 \mathrm{~g} / \mathrm{day}$ for a few weeks) are prebiotic (Bouhnik et al. 1996; Buddington et al. 1996; Gibson, 2000; Gibson et al. 1995; Kleessen et al. 1997; Roberfroid et al. 1998; Van Loo et al. 1998). as is the case with other dietary fibers, inulin and oligofructose have a bulking effect as well as an increase in stool frequency due to the increase in microbial biomass that results from their fermentation. Thus, inulin and oligofructose fit well within the current concept of dietary fiber especially its most recent definitions as proposed both by the American association of Cereal Chemists (2001) and the Food and Nutrition Board of the Institute of Medicine of the National Academy (2001), respectively.

Besides the properties reviewed here, concerning their role as fiber in the diet, inulin and oligofructose have been shown to induce interesting physiological/nutritional effects. These effects relate to improved calcium bioavailability, the reduction of risk of developing precancerous lesions in the colon, and hypotriglyceridemia and hypoinsulinemia in experimental models. These effects have been reviewed recently (Roberfroid \& Delzenne, 1998; Milner \& Roberfroid, 1999) and they are all extensively presented and discussed in this supplement issue.

But inulin and oligofructose also belong to other categories of functional food ingredients, which, by reference to the European consensus summarized earlier (Diplock et al. 1999) should have unique features such as:

- being part of conventional or everyday foods, to be consumed with the normal/usual diet

- being composed of naturally occuring (as opposed to synthetic) components, sometimes in increased concentrations or present in foods that would not normally supply them, and

- having a positive effect on target function(s) that may enhance well-being and health and/or reduce the risk of disease.

Inulin and oligofructose are indeed present in commonly consumed plants, they can be added to normal food products, they modulate key physiological functions like calcium absorption or possibly lipid metabolism, they modulate the composition of gut microflora, which plays a major role in gastrointestinal physiology, and finally they might play a role in reducing the risk of colon cancer (Pool-Zobel et al. 2002) Thus scientific data exist to substantiate type A claims (e.g. enhanced colonic func- tions, enhanced calcium absorption). Moreover sound hypotheses do already exist to justify further human nutrition studies as well as long-term intervention trials that might, in the future, give support to new type A but also possibly type B claims (e.g. reduction of the risk of bone disease or the risk of developing precancerous lesions...). Once again it is the objective of this as well as the previous publications of the like (ORC 2 Journal of Nutrition) to review, discuss and evaluate these data.

\section{References}

Alles MS, Hautvast JGA, Nagengast FM, Hartemink R, Van Laere KMJ \& Jansen JBM (1996) Fate of fructo-oligosaccharides in the human intestine. British Journal of Nutrition 76, 211-221.

American Association of Cereal Chemists (2001) The definition of dietary fiber. Report of the Dietary fiber definition committee to the Board of Directors. DF DEF 1/10/2001.

Bouhnik Y, Flourie B, Riottot M, Bisetti N, Gailing M \& Guibert A (1996) Effects of fructo-oligosaccharides ingestion on fecal bifidobacteria and selected metabolic indexes of colon carcinogenesis in healthy humans. Nutrition and Cancer 26, 21-29.

Buddington RK, Williams CH, Chen S \& Witherly SA (1996) Dietary supplement of neosugar alters fecal flora and decreases activities of some reductive enzymes in human subjects. American Journal of Clinical Nutrition 63, 709-716.

Codex Alimentarius (1991) Codex General Guidelines on Claims, CAC/GL 1 Revision 1.

De Bruyn A, Alvarez AP, Sandra P \& De Leenheer L (1992) Isolation and identification of O- $\beta$-D-fructofuranosyl- $(2 \rightarrow 1)$ O- $\beta$-D-fructosuranosyl- $(2 \rightarrow 1)$-D-fructose, a product of the enzymic hydrolysis of the inulin from Cichorium intybus. Carbohydrate Research 235, 303-308.

Delzenne N \& Roberfroid M (1994) Physiological effects of non digestible oligosaccharides. Lebensmittel Wissenschaft und Technologie 27, 1-6.

Diplock AT, Aggett PJ, Ashwell M, Bornet F, Fern EB \& Roberfroid MB (1999) Scientific concepts of functional foods in europe: consensus document. British Journal of Nutrition 81, suppl 1, S1-S28.

Ellegärd L, Andersson H \& Bosaeus I (1997) Inulin and oligofructose do not influence the absorption of cholesterol, and the excretion of cholesterol, $\mathrm{Fe}, \mathrm{Ca}, \mathrm{Mg}$ and bile acids but increases energy excretion in man. A blinded controlled cross-over study in ileostomy subjects. European Journal of Clinical Nutrition 51, 1-5.

Food and Nutrition Board (1989) Diet and Health, Implications for Reducing Chronic Diseases, 10th edition, Washington DC: National Academic Press.

Food and Nutrition Board of the Institute of Medicine of the National Academy (2001) Dietary Reference Intakes: Proposed definition of dietary fiber. Washington, DC: National Academy Press.

Franck A (2002) Technological functionality of inulin and oligofructose. British Journal of Nutrition 87, S287-S291, this issue.

Gibson GR (2000) Dietary modulation of the human gut microflora using the prebiotic inulin and oligofructose. Journal of Nutrition 129, suppl 7S, 1438S-1441S.

Gibson GR, Beatty ER, Wang X \& Cummings JH (1995) Selective stimulation of bifidobacteria in the human colon by oligofructose and inulin. Gastroenterology 108, 975-982.

James WPT (1988) Healthy Nutrition: Preventing Nutritionrelated Diseases in Europe. WHO, Regional Publications European Series 24, 4-6. 
Kleessen B, Sykura B, Zunft HJ \& Blaut M (1997) Effects of inulin and lactose on fecal microflora, microbial activity, and bowel habit in elderly constipated persons. American Journal of Clinical Nutrition 65, 1397-1402.

Knudsen KEB \& Hessov I (1995) Recovery of inulin from Jerusalem artichoke (Helianthus tuberosus 1.) in the small intestine of man. British Journal of Nutrition 74, 101-113.

McBain A \& Macfarlane G (1997) Investigations of bifidobacterial ecology and oligosaccharide metabolism in a three-stage compound continuous culture system. Scandinavian Journal of Gastroenterology 222, suppl, 32-40.

Milner J (2000) Functional foods and nutraceuticals: the US perspective, 17th Ross Conference on Medical Issues. American Journal of Clinical Nutrition 71, suppl, 16545-16595.

Milner J \& Roberfroid M (1999) Nutritional and health benefits of inulin and oligofructose. Journal of Nutrition 129, suppl. 7S, 1394 S-1502S.

Molis C, Flourie B, Ouarne F, Gailing MF, Lartigue S \& Guibert A, et al. (1996) Digestion, excretion, and energy value of fructooligosaccharides in healthy humans. American Journal of Clinical Nutrition 64, 324-328.

MoshFegh AJ, Friday JE, Goldman JP \& Chug Ahuga JK (1999) Presence of inulin and oligofructose in the diets of Americans. Journal of Nutrition 129, suppl 7S, 1407S-1411S.

Pool-Zobel B, Van Loo J, Rowland J \& Roberfroid M (2002)
Review of experimental evidence investigating the potential of prebiotic carbohydrates inulin and oligofructose to reduce the risk of colon cancer. British Journal of Nutrition 87, S273-S281, this issue.

Roberfroid MB \& Delzenne N (1998) Dietary fructans. Annual Review Nutrition 18, 117-143.

Roberfroid MB \& Slavin J (2000) Nondigestible oligosaccharides. Critical Review in Food Science and Nutrition 40, 461-480.

Roberfroid MB, Van Loo JAE \& Gibson GR (1998) The bifidogenic nature of chicory inulin and its hydrolysis products. Journal of Nutrition 128, 11-19.

Van Loo J, Coussement P, De Leenheer L, Hoebregs H \& Smits $\mathrm{G}$ (1995) On the presence of inulin and oligofructose as natural ingredients in the Western diet. Critical Reviews in Food Science and Nutrition 35, 525-552.

Van Loo J, Franck A, Cummings JH, Macfarlane GT, Englyst HN \& Quigley ME, et al. (1998) Consensus document on the functional food properties of non digestible oligosaccharides (DGXII ENDO Project). British Journal of Nutrition 81, $121-132$.

Welsch S (1996) Nutrient standards, dietary guidelines and food guides. In Present Knowledge in Nutrition, [EE Ziegler and LJ Filer, editors]. Washington, DC: ILSI Press.

Ziesenitz SC \& Siebert G (1987) In vitro assessment of Nystose as a sugar substitute. Journal of Nutrition 117, 846-851. 